\title{
Comparison of procalcitonin and high- sensitivity C-reactive protein for the diagnosis of sepsis and septic shock in the oldest old patients
}

\author{
Hongmin Zhang, Xiaoting Wang, Qing Zhang, Ying Xia and Dawei Liu*
}

\begin{abstract}
Background: Although the role of serum procalcitonin (PCT) and high-sensitivity C-reactive protein (hs-CRP) in the diagnosis of sepsis and septic shock is well studied, it has not been investigated among oldest old patients. The aim of our study is to determine the role of PCT and hs-CRP in the assessment of sepsis and septic shock in this specific group of patients in the ICU.

Methods: This is a prospective observational study. Patients $>85$ years of age admitted to the ICU from May 1st, 2016 to February 1st, 2017 were evaluated. Patients were divided into a sepsis and septic shock group(sepsis/SS) and a non-sepsis group. Serum levels of PCT, hs-CRP and the WBC were measured within $12 \mathrm{~h}$ of admission.

Results: A total of 70 patients aged 85 years and older were enrolled in this study. Fifty patients were labelled as sepsis/SS and the other 20 were labelled non-sepsis. A ROC analysis showed that the area under the curves (AUC) of hs-CRP and PCT for the discrimination of sepsis/SS patients were 0.825 (95\% confidence interval[CI]: 0.73-0. 92; $P<0.001)$ and $0.819(95 \% \mathrm{Cl}: 0.72-0.92 ; p<0.001)$, respectively. In a subgroup analysis of the sepsis/SS group, 27 patients had sepsis, while the other 23 patients had septic shock. The ROC analysis showed that the AUCs of hs-CRP and PCT for the discrimination of septic shock patients from sepsis patients were 0.751 (95\% Cl: $0.62-0.88 ; P=0.002$ ) and 0.719 (95\% Cl:0.57-0.86; $p=0.007$ ), respectively.
\end{abstract}

Conclusion: For the oldest old patients, hs-CRP is not inferior to PCT in the diagnosis of sepsis and septic shock.

Keywords: Procalcitonin, High-sensitivity C-reactive protein, Sepsis, Septic shock, Oldest old

\section{Background}

According to population statistics, individuals 85 years and older (oldest old) make up $1.8 \%$ of the total population but they account for $8 \%$ of all hospital discharges [1]. The oldest old age group is the fastest growing segment of the elderly population [2, 3]. As the geriatric population continues to grow, the number of oldest old patients admitted to the intensive care unit (ICU) will increase accordingly.

Sepsis is the leading cause of mortality in critically ill patients. Despite that the overall mortality rate of sepsis

\footnotetext{
*Correspondence: dwliu2015@sina.com

Department of Critical Care Medicine, Peking Union Medical College Hospital, Chinese Academy of Medical Sciences, 1\# Shuai Fu Yuan, Dong

Cheng District, Beijing 100730, China
}

patients is declining, the incidence of sepsis and the number of sepsis-related deaths are still increasing [4]. The elderly, especially those older than 80 years of age, frequently display non-specific signs and symptoms of acute infection that often present the physician with a diagnostic challenge [5]. The ability to diagnose or exclude suspected sepsis is vitally important for patient outcomes.

Procalcitonin (PCT) and high-sensitivity C-reactive protein (hs-CRP) are the most frequently used biomarkers for critically ill patients in whom sepsis is suspected [6]. PCT is usually considered to have a higher capacity than hsCRP in the diagnosis of sepsis $[7,8]$. However, whether PCT is still more useful than hs-CRP in diagnosing sepsis in oldest old patients has not been investigated. We 
hereby performed this study to compare the efficacy of PCT and hs-CRP in the diagnosis of sepsis and septic shock in oldest old patients.

\section{Methods}

\section{Study design and patient population}

This is a prospective observational study conducted at Peking Union Medical College Hospital. Patients aged above 85 years and older admitted to intensive care unit from May 1st, 2016 to February 1st, 2017 were studied. Patients were admitted either from medical ward where the patients have been treated for several days to several weeks or from emergency room. The main reasons that they were transferred to ICU include respiratory failure, shock, renal failure and high risk surgery. Based on the evaluation of physician, blood tests were taken when infection was suspected. The diagnosis of sepsis was made based on the new definition developed by the Sepsis Definitions Task Force: sepsis is defined as lifethreatening organ dysfunction caused by a dysregulated host response to infection. Organ dysfunction can be identified as an acute change in total SOFA score 2 points subsequent to the infection. Septic shock is defined as sepsis patients who have persistent hypotension that requires vasopressors to maintain a $\mathrm{MAP} \geq 65 \mathrm{mmHg}$ and who have a serum lactate level $>2 \mathrm{mmol} / \mathrm{L}$ despite adequate volume resuscitation [9]. Patients were excluded if they had any of the following conditions: a lack of informed consent, survival less than $12 \mathrm{~h}$, neutropenia, chemotherapy during the previous 90 days, or the withholding of life support.

\section{Laboratory testing}

All blood samples were drawn within $12 \mathrm{~h}$ of ICU admission. The PCT level was measured using the electrochemical luminescence method (VIDAS Brahms PCT, Mannheim, Germany) and the CRP level was measured using an immunoturbidimetric assay (Beckman, Carlsbad, CA 92010, USA). Lactate levels were measured using a blood-gas analyser (GEM 3000, USA).

\section{Statistical analysis}

Statistical analysis was performed using the SPSS version 13.0 statistical software package (SPSS Inc., Chicago Illinois, USA). Continuous data were expressed as the mean \pm standard deviation when normally distributed. Non-normally distributed variables were expressed as medians and interquartile ranges. Categorical variables were presented as numbers and percentages. Differences in clinical and laboratory findings were assessed using unpaired t-tests, Mann-Whitney U tests and chi-square tests or exact Fisher's tests, when appropriate. A correlation analysis between PCT, hs-CRP and SOFA score was performed using a nonparametric Spearman's test. Receiver operating characteristic (ROC) curves and the areas under each respective curve were calculated. The maximum PCT and CRP concentrations, and the white blood cell (WBC) in the first $12 \mathrm{~h}$ were used to calculate the ROC curves. Statistical significance was defined as $\mathrm{p}<0.05$.

\section{Ethics, consent and permissions}

The study was conducted according to the Declaration of Helsinki and was approved by the ethics committee of our institution (Approval Number: JS1300). Written informed consent was obtained from all patients or the next of kin if patients were unconscious or in a state of altered mentation.

\section{Results}

\section{General characteristics of all patients}

A total of 70 patients aged 85 years and older were enrolled in this study. Fifty patients were labelled sepsis/SS, and the other 20 patients were labelled non-sepsis. The general characteristics are illustrated in Table 1 . The two groups showed no difference regarding age. The mean ages in the sepsis/SS group and the non-sepsis group were 92.6 years and 92.7 years respectively, and $81.6 \%$ vs $75.0 \%$ were men, respectively. The sepsis/SS group had a higher peak temperature $\left(38.2^{\circ} \mathrm{C}\right.$ vs $\left.37.4^{\circ} \mathrm{C}, P=0.001\right)$ and higher lactate level $(2.3 \mathrm{mmol} / \mathrm{L}$ vs $1.3 \mathrm{mmol} / \mathrm{L}, P=0.023)$. The sepsis/SS group had a higher SOFA sore ( 8 vs $3, \mathrm{P}<0.001)$. The sepsis/SS group had a higher 28-day mortality than the non-sepsis group, but the difference was not statistically significant $(16 \%$ vs $5 \%, p=0.207)$.

\section{WBC, PCT and hs-CRP between sepsis/SS and non-sepsis group}

No difference was found in the WBC between the two groups. The CRP level and PCT level in the sepsis/SS group was significantly higher than that of the nonsepsis group. (Table 2).

The hs-CRP level and SOFA score were well correlated $(R=0.686, \mathrm{P}<0.001)$. The PCT level and SOFA were also correlated $(R=0.641, \mathrm{P}<0.001)$. The WBC level and SOFA score were poorly correlated $(R=0.037, P=0.764)$.

To evaluate the sensitivity and specificity of these three biomarkers, ROC curves were calculated (Fig. 1). The ROC analysis showed that hs-CRP was a good marker for the discrimination of sepsis/SS patients, with an area under the curve (AUC) of 0.825 (95\% confidence interval[CI]: 0.73-0.92; $\mathrm{P}<0.001)$. $\mathrm{PCT}$ was found to have an AUC of 0.819 (95\%CI: 0.72-0.92; $<<0.001)$, which was not statistically significant compared to hs-CRP ( $\mathrm{Z}=0.084, P=0.933$ ). The $\mathrm{WBC}$ was found to have an AUC of 0.606 (95\% CI:0.46-0.75; $p=0.170$ ).

For serum hs-CRP, the optimum cut-off value was $74.2 \mathrm{mg} / \mathrm{L}$, which resulted in a sensitivity of $78.0 \%$, a specificity of $75.0 \%$, a positive predictive value (PPV) of 
Table 1 General characteristics of the sepsis/SS and non-sepsis group

\begin{tabular}{|c|c|c|c|}
\hline Categories & Sepsis/SS group $(n=50)$ & Non-sepsis $\operatorname{group}(n=20)$ & $p$ value \\
\hline Age (yr) & $92.6 \pm 4.5$ & $92.7 \pm 3.2$ & 0.992 \\
\hline Sex (male, \%) & $40(81.6 \%)$ & $15(75.0 \%)$ & 0.553 \\
\hline \multicolumn{4}{|l|}{ Diagnosis } \\
\hline Pneumonia & 37 (74.0\%) & 0 & - \\
\hline Biliary tract infection & $6(12.0 \%)$ & 0 & - \\
\hline Enteral infection & $3(6.0 \%)$ & 0 & - \\
\hline UTI & $3(6.0 \%)$ & 0 & - \\
\hline CRBSI & $1(2.0 \%)$ & 0 & \\
\hline Cerebral disease $^{a}$ & 0 & $8(40.0 \%)$ & - \\
\hline Heart failure & 0 & $5(25.0 \%)$ & - \\
\hline GIB & 0 & $3(15.0 \%)$ & - \\
\hline Renal failure & 0 & $2(10.0 \%)$ & - \\
\hline asthma & 0 & $2(10.0 \%)$ & - \\
\hline \multicolumn{4}{|l|}{ Medical history } \\
\hline Stroke & $27(54.0 \%)$ & $11(55.0 \%)$ & 0.958 \\
\hline Cancer & $16(32.0 \%)$ & $6(30.0 \%)$ & 0.864 \\
\hline CKD & $12(24.0 \%)$ & $7(35.0 \%)$ & 0.341 \\
\hline$C A D$ & $29(58.0 \%)$ & $13(65.0 \%)$ & 0.589 \\
\hline HTN & $36(72.0 \%)$ & $15(75.0 \%)$ & 0.812 \\
\hline DM & $14(28.0 \%)$ & $8(40.0 \%)$ & 0.333 \\
\hline COPD & $13(26.0 \%)$ & $5(25.0 \%)$ & 0.952 \\
\hline Peak Temperature $\left({ }^{\circ} \mathrm{C}\right)$ & $38.2(37.6-38.7)$ & $37.4(36.6-37.9)$ & 0.001 \\
\hline Lactate(mmol/L) & $2.3(1.4-3.4)$ & $1.3(1.0-1.8)$ & 0.023 \\
\hline SOFA & $8(5-10)$ & $3(2-4)$ & 0.000 \\
\hline 28 day mortality & $8(16.0 \%)$ & $1(5.0 \%)$ & 0.207 \\
\hline
\end{tabular}

UTI urinary tract infection, CRBSI catheter-related bloodstream infection, GIB gastrointestinal bleeding, CKD chronic kidney dysfunction, CAD coronary artery disease, HTN hypertension, DM diabetes mellitus, COPD chronic obstructive pulmonary disease, SOFA sequential organ failure assessment

${ }^{a}$ cerebral disease: acute stroke, head injury, status epilepsy

$88.6 \%$ and a negative predictive value (NPV) of $57.7 \%$. For serum PCT, the optimum cut-off value was $0.45 \mathrm{ng} /$ $\mathrm{ml}$, which resulted in a sensitivity of $72.0 \%$, a specificity of $70.0 \%$, a PPV of $85.7 \%$ and an NPV of $50.1 \%$. For a serum PCT value of $0.25 \mathrm{ng} / \mathrm{ml}$, the sensitivity and specificity were $88.0 \%$ and $65.0 \%$, PPV and NPV were $86.2 \%$ and $68.4 \%$, respectively.

\section{Subgroup analysis of sepsis/SS group}

Of the 50 sepsis/SS patients, 27 patients had sepsis, while the other 23 patients had septic shock. The two groups showed no differences in either age or sex. The sepsis group had more pneumonia patients, but this result was not statistically significant $(23 / 27$ vs $14 / 23, p=0.052)$. The sepsis group had less patients with biliary infections $(1 / 27$ vs $5 / 23$, $p=0.048)$. The sepsis and septic shock group had similar peak temperatures $\left(38.0{ }^{\circ} \mathrm{C}\right.$ vs $\left.38.3^{\circ} \mathrm{C}, p=0.283\right)$. The septic shock group had higher lactate levels $(2.3 \mathrm{mmol} / \mathrm{L}$ vs $1.3 \mathrm{mmol} / \mathrm{L}, \mathrm{p}<0.001)$ and higher SOFA scores (10 vs 6 , $\mathrm{p}<0.001)$. No difference was found regarding comorbidities between the two groups. The septic shock group had a higher mortality rate $(30.4 \%$ vs $3.7 \%, p=0.011)$.

Table 2 Biomarkers between sepsis/SS and non-sepsis group

\begin{tabular}{llll}
\hline Categories & Sepsis/SS group $(n=50)$ & Non-sepsis group $(n=20)$ & $p$ value \\
\hline WBC $\left(\times 10^{9} / \mathrm{L}\right)$ & $11.9(7.9-15.3)$ & $9.7(7.3-13.4)$ & 0.170 \\
hs-CRP $(\mathrm{mg} / \mathrm{L})$ & $143.4(82.6-212.4)$ & $50.9(32.3-74.1)$ & 0.000 \\
PCT $(\mathrm{ng} / \mathrm{ml})$ & $0.84(0.36-5.8)$ & $0.08(0.05-0.54)$ & 0.000
\end{tabular}

WBC white blood cell, $h s-C R P$ high-sensitivity C-reactive protein, $P C T$ procalcitonin 


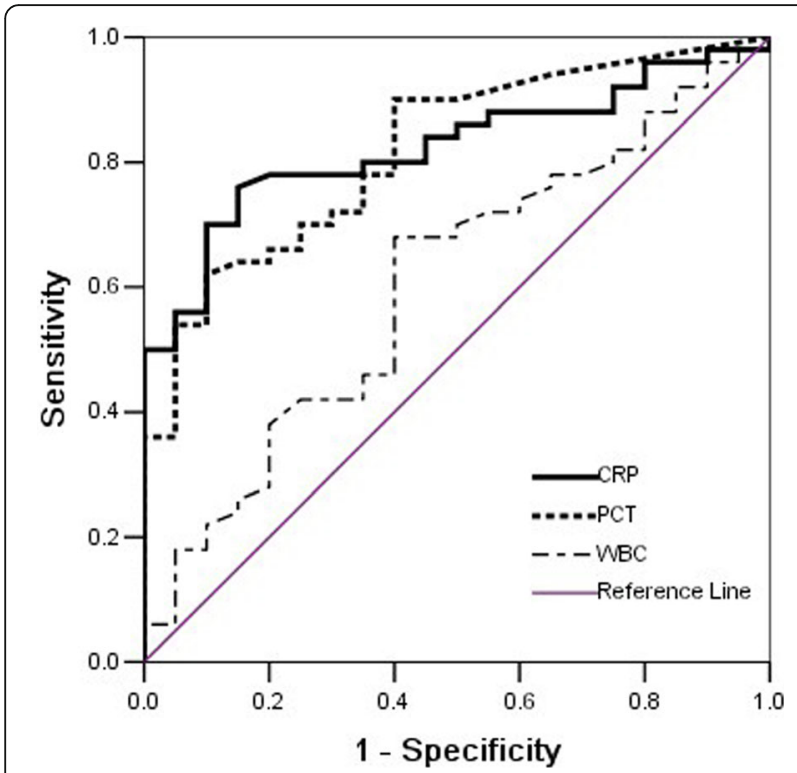

Fig. 1 Diagnostic values of CRP, PCT, WBC for sepsis/SS, estimated by receiver operating curve (ROC) analysis. CRP area 0.825 (95\% Cl 0.73-0.92), $P<0.001 ;$ PCT area 0.819 (95\% Cl 0.71-0.92), $P<0.001$; WBC area 0.606 (95\% Cl 0.46-0.75), $P=0.170$. sepsis $/ S S$ : sepsis/septic shock

No difference in the WBC was found between the two groups. The CRP level and PCT level in the septic shock group was significantly higher than that in the sepsis group. (Table 3) To evaluate the sensitivity and specificity of these three biomarkers, ROC curves were calculated (Fig. 2). The ROC analysis showed that hs-CRP was a good marker that discriminated septic shock patients from sepsis patients, with an AUC of $0.751 \quad(95 \%$ CI: 0.62-0.88; $P=0.002)$. PCT was found to have an AUC of 0.719 (95\% CI: 0.57-0.86; $p=0.007$ ), which was not statistically different from CRP $(\mathrm{z}=0.323, p=0.747)$. The WBC was found to have an AUC of 0.613 (95\% CI: $0.45-0.77 ; p=0.165)$.

For serum hs-CRP, the optimum cutoff value for the diagnosis of septic shock was $139.4 \mathrm{mg} / \mathrm{L}$, which resulted in a sensitivity of $70.8 \%$, a specificity of $65.4 \%$, PPV of $63.6 \%$ and an NPV of $72.4 \%$. For serum PCT, the optimum cut-off value was $0.75 \mathrm{ng} / \mathrm{ml}$, which resulted in a sensitivity of $70.8 \%$, a specificity of $61.5 \%$, a PPV of $61.4 \%$ and an NPV of $71.2 \%$.

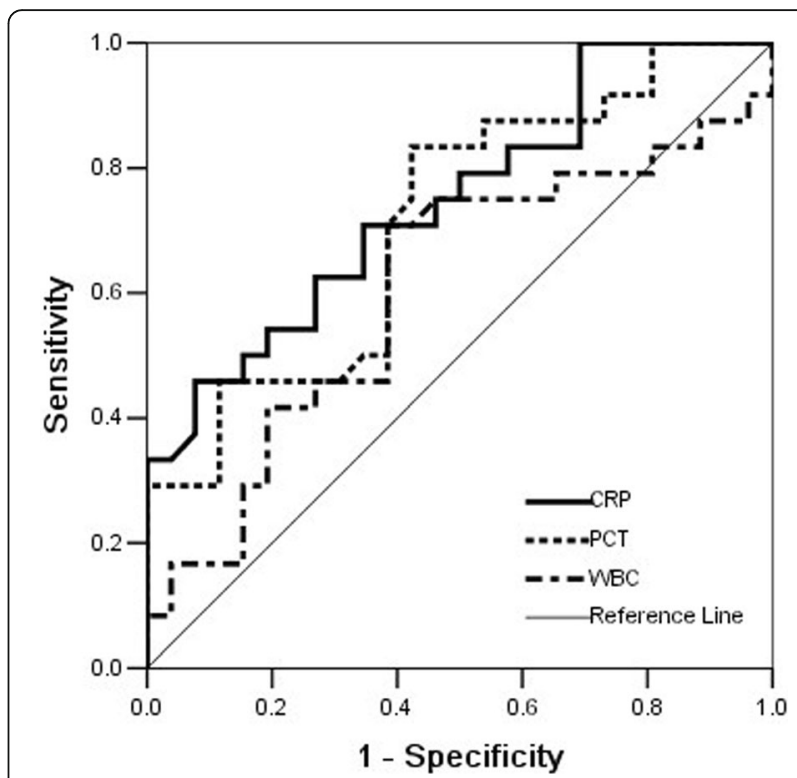

Fig. 2 Diagnostic values for septic shock of hs-CRP, PCT, WBC, estimated by receiver operating curve (ROC) analysis. hs-CRP area 0.751 (95\% Cl $0.62-0.88), P=0.002 ; \mathrm{PCT}$ area 0.719 (95\% Cl 0.57-0.86), $P=0.007$; WBC area $0.606(95 \% \mathrm{Cl} 0.45-0.77), P=0.165$

\section{Discussion}

In this study, we found that hs-CRP was as good as PCT for the diagnosis of sepsis and septic shock among the oldest old patients. To our knowledge this is the first study that enrolled exclusively oldest old patients to evaluate and compare the diagnostic accuracy of PCT and CRP.

In the guideline issued by the Surviving Sepsis Campaign, sepsis and septic shock were labelled as medical emergencies, which necessitate immediate treatment and resuscitation [10]. The geriatric population is rapidly expanding, with the oldest old segment ( $\geq 85 \mathrm{yr}$ ) growing fastest [11]. Compared to adult patients, oldest old patients have fewer signs and symptoms of infection and more easily to develop organ failure [12]. Therefore, early diagnosis would be more meaningful in this population.

We noted in our study that leukocytosis was not a sensitive marker for sepsis or septic shock because no difference was observed between the non-sepsis and sepsis/SS groups. Febrile responses to infectious diseases in geriatric patients are often blunted or absent; the presence of fever may often indicate a significant infection, but the absence

Table 3 Biomarkers between sepsis and septic shock group

\begin{tabular}{llll}
\hline Categories & Sepsis group $(n=27)$ & Septic shock group $(n=23)$ & $p$ value \\
\hline WBC $\left(\times 10^{9} / \mathrm{L}\right)$ & $11.5(7.5-15.8)$ & $12.5(8.6-16.1)$ & 0.282 \\
CRP $(\mathrm{mg} / \mathrm{L})$ & $118.1(46.2-177.1)$ & $180.2(115.7-248.0)$ & 0.003 \\
$P C T(\mathrm{ng} / \mathrm{ml})$ & $0.61(0.27-2.07)$ & $1.00(0.71-25.03)$ & 0.009 \\
\hline
\end{tabular}


of fever does not reliably exclude serious illness [13]. Our study found that peak temperature was higher in the sepsis/SS group than in the nonsepsis group. However, no difference was found in the peak temperatures between the sepsis and septic shock groups.

The advantage of the PCT lies in its high specificity, with minimal or no increase in viral infection, cardiogenic shock, and non-infectious SIRS [14-16]. The C-reactive protein is one of the most widely used indicators for the response of acute-phase proteins. The measurement of serum CRP can help to differentiate inflammatory conditions from non-inflammatory conditions and are useful in managing the patient's disease because the concentration often reflects the response to, and need for, therapeutic intervention [17]. The PCT and CRP levels were not well correlated in a prior study [18]. Another previous study found that PCT was better than CRP in a group of adult patients, with AUCs of 0.925 vs 0.677 for the diagnosis of sepsis. They discovered that SOFA scores were associated with PCT levels, $r=0.73$, while the association with CRP was much lower, $r=0.41$ [8]. Another study on critically ill neonates and children drew the same conclusion [19]. However, Steichen $\mathrm{O}$ et al. demonstrated that the clinical usefulness of PCT to diagnose invasive bacterial infections in elderly patients appears to be very limited [20]. Nouvenne A et al. noted that, for elderly patients, hs-CRP is more useful than PCT in diagnosing pneumonia [21].

In this study, we found that PCT was not better than hs-CRP in oldest old patients. Usually, PCT often has a high negative predictive value [22]. However, in this specific population, the negative predictive value of PCT was lower than hs-CRP both in the diagnosis of sepsis and in septic shock. A PCT cutoff of $0.5 \mathrm{ng} / \mathrm{mL}$ is frequently cited for the diagnosis of bacterial sepsis and bacteremia in adult patients [23, 24]. However, the PCT tends to be lower in elderly patients. In a group of elderly people $(>65 \mathrm{yr})$, a PCT level of $0.2 \mathrm{ng} / \mathrm{ml}$ is sensitive for bacteraemia [25]. In this study, we also discovered that the best cut-off value for sepsis/SS was $0.45 \mathrm{ng} / \mathrm{ml}$. Despite that CRP was deemed to be nonspecific, a previous study indicated that when there is a CRP level greater than $100 \mathrm{mg} / \mathrm{L}, 80-85 \%$ of patients have bacterial infections [26]. Additionally, CRP has a broad abnormal range, and we demonstrated that levels at or above $74.2 \mathrm{mg} / \mathrm{L}$ should indicate the suspicion of sepsis, while levels at or above $139.4 \mathrm{mg} / \mathrm{L}$ highly suggestive of septic shock in oldest old patients.

The definition of sepsis was adjusted by replacing systemic inflammatory response syndrome (SIRS) criteria with the sequential organ failure assessment (SOFA) score [27]. In this study, we found that CRP was well correlated to the SOFA score, which made hs-CRP an adequate biomarker to reflect the severity of sepsis in oldest old patients. The hs-CRP has often been deemed to be a nonspecific indicator of systemic inflammation and will be elevated in many non-infectious circumstances [28, 29]. Povoa P, et al. demonstrated in their study that plasma CRP levels were significantly related to the infectious status, and they noted the superiority of hs-CRP to BT and WBC in their study. They also found that a plasma CRP level of $50 \mathrm{mg} / \mathrm{L}$ or more was highly suggestive of sepsis in a group of adult patients with an average age of 61.3 years [30].

There are some limitations that should be considered. First, serial measurements of PCT and CRP were not performed. A serial blood test of CRP in previous study demonstrated the peak level of CRP was within 24-48 h during sepsis [31]. However, elevated levels of hs-CRP were detected within $12 \mathrm{~h}$ of ICU admission in this study. Furthermore, we also discovered a broad distribution of hs-CRP levels, which correlated well with SOFA scores. Several prior studies have also evaluated the same time point, and they also detected elevated CRP levels $[19,32,33]$. Second, the sample was not large enough because the oldest old patients are still a small proportion of ICU patients. Third, the sex was not equally distributed in this oldest old group because male patients accounted for the majority. More female patients need to be studied before the same conclusion can be used in this population.

\section{Conclusions}

The results of the present study suggest that hs-CRP is not inferior to PCT in the diagnosis of sepsis and septic shock in oldest old patients.

\section{Abbreviations \\ AUC: Area under the curve; hs-CRP: High-sensitivity C-reactive protein; ICU: Intensive care unit; NPV: Negative predictive value; PCT: Procalcitonin; PPV: Positive predictive value; ROC: Receiver operating characteristic; SIRS: Systemic inflammatory response syndrome; SOFA: Sequential organ failure assessment; WBC: White blood cell}

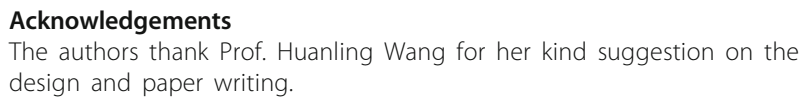

Availability of data and materials

The datasets used and/or analyzed during the current study are available from the corresponding author on reasonable request.

\section{Authors' contributions}

ZHM interpreted data and performed the statistical analysis and drafted the manuscript; WXT help obtained clinical data and revised the manuscript; ZQ obtained data and revised the manuscript; XY help obtained clinical data and revised the manuscript; LDW conceived and designed the study and revised the manuscript. All authors have read and approved the final manuscript. 


\section{Ethics approval and consent to participate}

This study was approved by the ethics committee of Peking Union Medical College Hospital (Approval Number: JS1300). Written informed consent was obtained from all patients or the next of kin.

\section{Consent for publication}

Not applicable.

\section{Competing interests}

The authors declare that they have no competing interests.

\section{Publisher's Note}

Springer Nature remains neutral with regard to jurisdictional claims in published maps and institutional affiliations.

Received: 31 March 2017 Accepted: 25 July 2017

Published online: 01 August 2017

\section{References}

1. Wier L, pfuntner A, C S. Hospital utilization among oldest adults. Statistical Brief \#103. 2008.

2. Wetle TF. The oldest old: missed public health opportunities. Am J Public Health. 2008:98:1159.

3. World population ageing. 1950-2050. New York (NY): United Nations Publications; 2002:23. http://www.unorg/esa/population/publications/world ageing. Accessed Apr 2002.

4. Martin GS, Mannino DM, Eaton S, Moss M. The epidemiology of sepsis in the United States from 1979 through 2000. N Engl J Med. 2003;348:1546-54.

5. Dwolatzky T, Clarfield AM, H. B. Non-specific presentations of illness. In: Jones R, Britten N, Culpepper L, Gass DA, Grol R, Mant D, Silagy C, editors. Oxford textbook of primary medical care. Oxford.: Oxford University Press; 2003. p. 1247-50.

6. Garnacho-Montero J, Huici-Moreno MJ, Gutierrez-Pizarraya A, Lopez I, MarquezVacaro JA, Macher $\mathrm{H}$, et al. Prognostic and diagnostic value of eosinopenia, $\mathrm{C}$ reactive protein, procalcitonin, and circulating cell-free DNA in critically ill patients admitted with suspicion of sepsis. Crit Care. 2014;18:R116.

7. Kibe S, Adams K, Barlow G. Diagnostic and prognostic biomarkers of sepsis in critical care. J Antimicrob Chemother. 2011;66(Suppl 2):ii33-40.

8. Luzzani A, Polati E, Dorizzi R, Rungatscher A, Pavan R, Merlini A. Comparison of procalcitonin and C-reactive protein as markers of sepsis. Crit Care Med. 2003;31:1737-41.

9. Singer M, Deutschman CS, Seymour CW, Shankar-Hari M, Annane D, Bauer $M$, et al. The third international consensus definitions for sepsis and septic shock (sepsis-3). JAMA. 2016;315:801-10.

10. Rhodes A, Evans LE, Alhazzani W, Levy MM, Antonelli M, Ferrer R, et al. Surviving sepsis campaign: international guidelines for Management of Sepsis and Septic Shock: 2016. Crit Care Med. 2017:45:1-67.

11. Schneider EL. Aging in the third millennium. Science. 1999;283:796-7.

12. Lee CC, Chen SY, Chang IJ, Chen SC, Wu SC. Comparison of clinical manifestations and outcome of community-acquired bloodstream infections among the oldest old, elderly, and adult patients. Medicine (Baltimore). 2007:86:138-44.

13. Harris RL, Musher DM, Bloom K, Gathe J, Rice L, Sugarman B, et al. Manifestations of sepsis. Arch Intern Med. 1987;147:1895-906.

14. Rintala EM, Aittoniemi J, Laine S, Nevalainen TJ, Nikoskelainen J. Early identification of bacteremia by biochemical markers of systemic inflammation. Scand J Clin Lab Invest. 2001;61:523-30.

15. de Werra I, Jaccard C, Corradin SB, Chiolero R, Yersin B, Gallati H, et al. Cytokines, nitrite/nitrate, soluble tumor necrosis factor receptors, and procalcitonin concentrations: comparisons in patients with septic shock, cardiogenic shock, and bacterial pneumonia. Crit Care Med. 1997;25:607-13.

16. Guven H, Altintop L, Baydin A, Esen S, Aygun D, Hokelek M, et al. Diagnostic value of procalcitonin levels as an early indicator of sepsis. Am J Emerg Med. 2002;20:202-6.

17. Gabay C, Kushner I. Acute-phase proteins and other systemic responses to inflammation. N Engl J Med. 1999;340:448-54.

18. Meili M, Kutz A, Briel M, Christ-Crain M, Bucher HC, Mueller B, et al. Infection biomarkers in primary care patients with acute respiratory tract infectionscomparison of Procalcitonin and C-reactive protein. Bmc Pulm Med. 2016; 16:43.
19. Enguix A, Rey C, Concha A, Medina A, Coto D, Dieguez MA. Comparison of procalcitonin with $\mathrm{C}$-reactive protein and serum amyloid for the early diagnosis of bacterial sepsis in critically ill neonates and children. Intensive Care Med. 2001;27:211-5.

20. Steichen O, Bouvard E, Grateau G, Bailleul S, Capeau J, Lefervre G. Diagnostic value of procalcitonin in acutely hospitalized elderly patients. Eur J Clin Microbiol. 2009;28:1471-6.

21. Nouvenne A, Ticinesi A, Folesani G, Cerundolo N, Prati B, Morelli I, et al. The association of serum procalcitonin and high-sensitivity C-reactive protein with pneumonia in elderly multimorbid patients with respiratory symptoms: retrospective cohort study. BMC Geriatr. 2016;16:16.

22. Hoeboer SH, van der Geest PJ, Nieboer D, Groeneveld AB. The diagnostic accuracy of procalcitonin for bacteraemia: a systematic review and metaanalysis. Clin Microbiol Infect. 2015;21:474-81.

23. Simon L, Gauvin F, Amre DK, Saint-Louis P, Lacroix J. Serum procalcitonin and C-reactive protein levels as markers of bacterial infection: a systematic review and meta-analysis. Clin Infect Dis. 2004;39:206-17.

24. Tang BM, Eslick GD, Craig JC, McLean AS. Accuracy of procalcitonin for sepsis diagnosis in critically ill patients: systematic review and meta-analysis. Lancet Infect Dis. 2007;7:210-7.

25. Caterino JM, Scheatzle MD, Forbes ML, D'Antonio JA. Bacteremic elder emergency department patients: procalcitonin and white count. Acad Emerg Med. 2004;11:393-6.

26. Morley JJ, Kushner I. Serum C-reactive protein levels in disease. Ann N Y Acad Sci. 1982;389:406-18.

27. Shankar-Hari M, Phillips GS, Levy ML, Seymour CW, Liu VX, Deutschman CS, et al. Developing a new definition and assessing new clinical criteria for septic shock for the third international consensus definitions for sepsis and septic shock (sepsis-3). JAMA. 2016;315:775-87.

28. Ridker PM. Inflammatory biomarkers and risks of myocardial infarction, stroke, diabetes, and total mortality: implications for longevity. Nutr Rev. 2007:65:S253-9.

29. Lloyd-Jones DM, Liu K, Tian L, Greenland P. Narrative review: assessment of $\mathrm{C}$-reactive protein in risk prediction for cardiovascular disease. Ann Intern Med. 2006;145:35-42.

30. Povoa P, Almeida E, Moreira P, Fernandes A, Mealha R, Aragao A, et al. Creactive protein as an indicator of sepsis. Intensive Care Med. 1998;24:1052-6.

31. Castelli GP, Pognani C, Meisner M, Stuani A, Bellomi D, Sgarbi L. Procalcitonin and $\mathrm{C}$-reactive protein during systemic inflammatory response syndrome, sepsis and organ dysfunction. Crit Care. 2004;8:R234-42.

32. Yang Y, Xie J, Guo F, Longhini F, Gao Z, Huang Y, et al. Combination of Creactive protein, procalcitonin and sepsis-related organ failure score for the diagnosis of sepsis in critical patients. Ann Intensive Care. 2016;6:51.

33. Gibot S, Bene MC, Noel R, Massin F, Guy J, Cravoisy A, et al. Combination biomarkers to diagnose sepsis in the critically ill patient. Am J Respir Crit Care Med. 2012;186:65-71.

\section{Submit your next manuscript to BioMed Central and we will help you at every step:}

- We accept pre-submission inquiries

- Our selector tool helps you to find the most relevant journal

- We provide round the clock customer support

- Convenient online submission

- Thorough peer review

- Inclusion in PubMed and all major indexing services

- Maximum visibility for your research

Submit your manuscript at www.biomedcentral.com/submit
C) Biomed Central 